JURNAL SIMETRIK VOL.9, NO.2, DESEMBER 2019

\title{
TINJAUAN PENERAPAN SISTEM MANAJEMEN KESELAMATAN DAN KESEHATAN KERJA PADA PROYEK BANGUNAN PEMERINTAH TIDAK SEDERHANA DI KOTA AMBON
}

\author{
Grace Lelapary $^{1)}$, Imran Oppier²), Christy Gery Buyang ${ }^{3)}$ \\ ${ }^{1,2,3)}$ Program Studi Teknik Sipil, Universitas Pattimura \\ ${ }^{1)}$ gracelelapary03@gmail.com, ${ }^{2}$ oppier.iwan@ @mail.com, ${ }^{3)}$ christ.gery@gmail.com
}

\begin{abstract}
Ambon City is one of the cities whose development is being intensively carried out by the government, therefore many government buildings have been carried out in Ambon City. Many workers are carried heavy work that have the potential to experience hazards, so that a good application of occupational safety and health (SMK3) is needed to reduce risk. This study aims to determine the level of implementation of the occupational safety and health management system in non-modest government building projects in Ambon City. The method used in this study is a quantitative method by observation and interview, this method tends to be descriptive results using Minister of Public Works Regulation No. 9 of 2008 and processed using a Likert Scale as a measure to determine the presentation of the application of SMK3 in the project under study. The results of the study on the first factor, namely regulatory factors and work safety standards which are the most fundamental barriers, are companies imposing sanctions with a percentage of $56.67 \%$, regulatory and operational factors, workers reject hazardous work with a $49.17 \%$ presentation on worker factors, the company provides emergency and fire extinguishers fires with a presentation of $48.33 \%$ on environmental factors of the project, workers get socialization with presentations of $55.83 \%$ on the factors of occupational safety and health management, and the company carries out periodic inspections of $27.50 \%$ on safety and health implementation factors .
\end{abstract}

\begin{abstract}
ABSTRAK
Kota Ambon merupakan salah satu kota yang pembangunannya sedang gencar dilakukan pemerintah, karena itu banyak bangunan pemerintah yang dilakukan di Kota Ambon. Banyak pekerja pada proyek melakukan pekerjaan berat yang sangat berpotensi mengalami bahaya, sehingga diperlukan penerapan keselamatan dan kesehatan kerja (SMK3) yang baik untuk dapat mengurangi resiko. Penelitian ini bertujuan untuk mengetahui tingkat pelaksanaan sistem manajemen keselamatan dan kesehatan kerja (SMK3) pada proyek bangunan pemerintah tidak sederhana (BPTS) di Kota Ambon. Metode yang diguankan pada penelitian ini adalah metode kuantitatif dengan cara observasi dan wawancara, metode ini cenderung pada hasil deskriptif dengan menggunakan Peraturan Menteri Pekerjaan Umum No. 9 Tahun 2008 dan diolah menggunakan Skala Likert sebagai ukuran untuk menentukan presentasi penerapan SMK3 pada proyek yang diteliti. Hasil penelitian pada faktor pertama yaitu faktor peraturan dan standar keselamatan kerja yang menjadi penghambat paling mendasar adalah perusahaan memberikan sanksi dengan presntasi $56.67 \%$, faktor peraturan dan operasional, pekerja menolak pekejaan yang membahayakan dengan presentasi $49.17 \%$ pada faktor pekerja, perusahaan menyediakan pintu darurat dan pemadam kebakaran dengan presentasi sebesar $48.33 \%$ pada faktor lingkungan proyek, pekerja mendapatkan sosialisasi dengan presentasi sebesar $55.83 \%$ pada faktor menajemen keselamatan dan kesehatan kerja, dan perusaah melakukan pemeriksaan berkala sebesar $27.50 \%$ pada faktor pelaksanaan K3.
\end{abstract}

Kata Kunci : Sistem Manajemen Keselamatan dan Kesehatan Kerja (SMK3); Bangunan Pemerintah Tidak Sederhana; Skala Likert

\section{PENDAhULUAN}

Pekerjaan konstruksi merupakan kegiatan yang cukup banyak menggunakan berbagai peralatan, baik canggih maupun manual. Peralatan ini dilaksanakan di lahan yang terbatas luasnya dalam berbagai jenis kegiatan sehingga menyebabkan resiko tinggi terhadap kecelakaan. Laporan International Labour Organization (ILO), setiap hari terjadi kecelakaan kerja yang mengakibatkan korban fatal sekitar 6000 kasus dan berdasarkan data BPJS Ketenagakerjaan Kota Ambon
Tahun 2017 ada 23 kasus kecelakaan kerja yang terjadi dan berakibat meninggal dunia. Untuk mengatasi hal tersebut, maka dilakukan tinjauan sistem yaitu penerapan Sistem Manajemen Keselamatan dan Kesehatan Kerja (SMK3). Karena pada prinsipnya kecelakaan kerja akibat perbuatan manusia (human error) bisa dicegah dengan pengawasan dan kualifikasi SMK3 yang diperketat oleh pengawasan dari pemerintah pusat maupun dinas. Artikel ini bertujuan untuk mengetahui tingkat penerapan dan pelaksanaan SMK3 


\section{JURNAL SIMETRIK VOL.9, NO.2, DESEMBER 2019}

serta memberi solusi bagi penerapan SMK3 yang belum dilakukan pada proyek pembangunan Gedung Pemerintah Tidak Sederhana di Kota Ambon.

\section{TINJAUAN PUSTAKA \\ 2.1 Defenisi SMK3}

Sistem Manajemen Keselamatan dan Kesehatan Kerja (SMK3) adalah bagian dari sistem manajemen secara keseluruhan yang meliputi struktur organisasi, perencanaan, tanggung jawab, pelaksanaan, prosedur, proses dan sumber daya yang dibutuhkan bagi pengembangan penerapan, pencapaian, pengkajian dan pemeliharaan kebijakan keselamatan dan kesehatan kerja guna terciptanya tempat kerja yang selamat, aman, efisien dan produktif. (Permen PU, 2008)

Pemahaman tentang SMK3 yang benar dari semua aspek sangat berguna untuk pencegahan kecelakaan dalam kegiatan konstruksi dimana diharapkan produksi meningkat dengan meminimalkan atau mengurangi kecelakaan bahkan meniadakan kecelakaan (zero accident).

Sesuai dengan Bab III pasal 3 Peraturan Menteri Tenaga Kerja No. PER. 05/MEN/1996, penerapan SMK3 diwajibkan kepada perusahaan dengan tingkat penerapan sebagai berikut :

1. Perusahaan kecil atau perusahaan dengan tingkat resiko rendah harus menerapkan sebanyak 64 elemen.

2. Perusahaan sedang atau perusahaan dengan tingkat resiko menengah harus menerapkan sebanyak 122 elemen.

3. Perusahaan besar atau perusahaan dengan tingkat resiko tinggi harus menerapkan sebanyak 166 elemen.

Dilihat dari tingkat penerapan di atas, maka pembangunan proyek gedung Siloam Hospital termasuk kategori perusahaan besar yang menerapkan sebanyak 166 elemen yang terdapat dalam SMK3. Hal dikarenakan proyek ini memiliki pekerja lebih dari 100 orang.

Keberhasilan penerapan Sistem Manajemen Keselamatan dan Kesehatan Kerja (SMK3) di tempat kerja dapat diukur menurut Permenaker 05/MEN/1996 sebagai berikut:

1. Untuk tingkat pencapaian 0-59 \% dan pelanggaran peraturan perundangan (nonconformance) dikenai tindakan hukum.

2. Untuk tingkat pencapaian 60-84 \% diberikan sertifikat dan bendera perak.

3. Untuk tingkat pencapaian 85-100 \% diberikan sertifikat dan bendera emas.

Ditinjau dari segi kinerja penerapan penyelenggaraan SMK3 konstruksi bidang Pekerjaan Umum menurut Permen PU Nomor: 09/PRT/2008 terbagi menjadi 3 (tiga) bagian, yaitu:

1. Baik, bila mencapai hasil penilaian $>85 \%$.

2. Sedang, bila mencapai hasil penilaian $60 \%-85 \%$.

p-ISSN: 2302-9579/e-ISSN: 2581-2866
3. Kurang, bila mencapai hasil penilaian $<60 \%$.

\subsection{Prinsip Dasar SMK3 dalam Perundang- undangan}

Prinsip dasar SMK3 sudah ada sejak tahun 1970 terlihat dalam Peraturan Undang-undang Republik Indonesia No. 1 tahun 1970 tentang Keselamatan Kerja yang menjelaskan bahwa bahwa setiap tenaga kerja berhak mendapat perlindungan atas keselamatan dalam melakukan pekerjaan untuk kesejahteraan dan meningkatkan produksi serta produktivitas nasional.

Sedangkan pada undang-undang No.13 tahun 2003 terdapat prinsip dasar SMK3 yang diatur dalam pasal 87 tentang ketenagakerjaan yang diantaranya berisi:

1. Setiap perusahaan wajib menerapkan sistem manjemen keselamatan dan kesehatan kerja yang terintegrasi dengan sistem manajemen perusahaan.

2. Ketentuan mengenai penerapan sistem manjemen keselamatan dan kesehatan kerja sebagaimana dimaksud dalam ayat (1) diatur dengan Peraturan Pemerintah.

Setelah itu, maka dikeluarkan Peraturan Menteri Tenaga Kerja Nomor: PER. 05/MEN/1996 tentang SMK3 dan dalam rangka mewujudkan tertib penyelenggaraan pekerjaan konstruksi demi tercapainya keamanan K3, maka ditetapkan Peraturan Menteri tentang Pedoman SMK3 kontruksi bidang Pekerjaan Umum Nomor: 09/PRT/2008 yang tercantum dalam ayat (a), (b) dan (c) sebagai berikut:

1. Ayat (a) menyatakan bahwa dalam rangka mewujudkan tertib penyelenggaraan pekerjaan konstruksi, penyelenggaraan pekerjaan konstruksi wajib memenuhi syarat-syarat keamanan, keselamatan dan kesehatan kerja pada tempat kegiatan konstruksi.

2. Ayat (b) menyatakan bahwa agar penyelenggaraan keamanan, keselamatan dan, kesehatan kerja pada tempat kegiatan konstruksi bidang Pekerjaan Umum dapat terselenggara secara optimal, maka diperlukan suatu pedoman pembinaan dan pengendalian sistem keselamatan dan kesehatan kerja pada tempat kegiatan konstruksi bidang Pekerjaan Umum.

3. Ayat (c) menyatakan bahwa berdasarkan pertimbangan sebagaimana dimaksud pada huruf a dan huruf $b$ perlu menetapkan Peraturan Menteri tentang Pedoman Sistem Keselamatan dan Kesehatan Kerja (K3) Konstruksi bidang Pekerjaan Umum.

Sebagaimana yang telah disebutkan dalam Permen PU Nomor: 09/PRT/M/2008 tentang pedoman SMK3 konstruksi bidang PU tercantum elemen-elemen yang harus dilaksanakan oleh Penyedia Jasa sebagai berikut:

1. Kebijakan K3

Kebijakan adalah arah yang ditentukan untuk dipatuhi dalam proses kerja dan organisasi perusahaan. Kebijakan yang ditetapkan manajemen menuntut partisipasi dan kerjasama semua pihak.Kebijakan K3 


\section{JURNAL SIMETRIK VOL.9, NO.2, DESEMBER 2019}

menggarisbawahi hubungan kerja manajemen dan karyawan dalam rangka pelaksanaan program K3 yang efektif.(Sastrohadiwiryo, 2001)

2. Perencanaan K3

Perusahaan harus membuat perencanaan yang efektif guna mencapai keberhasilan penerapan SMK3 dengan sasaran yang jelas dan dapat diukur.Perencanaan juga memuat tujuan, sasaran dan indikator kinerja yang diterapkan.(Sastrohadiwiryo, 2001). Adapun bagianbagian perencanaan adalah sebagai berikut:

1) Identifikasi Bahaya, Penilaian Risiko dan Pengendaliannya,

2) Pemenuhan Perundang-undangan dan persyaratan lainnya,

3) Sasaran dan Program. (Permen, 2008)

3. Penerapan dan Operasi Kegiatan

Dalam mencapai tujuan keselamatan dan kesehatan kerja, perusahaan harus menunjuk personel yang mempunyai kualifikasi yang sesuai dengan sistem yang diterapkan.Adapun kualifikasi yang tercantum dalam Permen No. 9 tahun 2008 adalah sebagai berikut:

1) Sumber Daya, Struktur Organisasi dan

Pertanggungjawaban.

2) Kompetensi, Pelatihan dan Kepedulian.

3) Komunikasi, Keterlibatan dan Konsultasi.

4) Dokumentasi.

5) Pengendalian Dokumen.

6) Pengendalian Operasional.

7) Kesiagaan dan Tanggap Darurat. (Permen, 2008)

4. Pemeriksaan atau Evaluasi

Berikut ini adalah bagian peraturan dalam setiap evaluasi atau pengukuran kinerja SMK3 terdiri dari 4 bagian yaitu:

1) Evaluasi Kepatuhan.

2) Penyelidikan Insiden, Ketidaksesuaian, Tindakan Perbaikan dan Pencegahan.

3) Pengendalian Rekaman.

4) Audit Internal.(Permen, 2008)

5. Tinjauan Manajemen (Permen, 2008)
3. METODOLOGI PENELITIAN

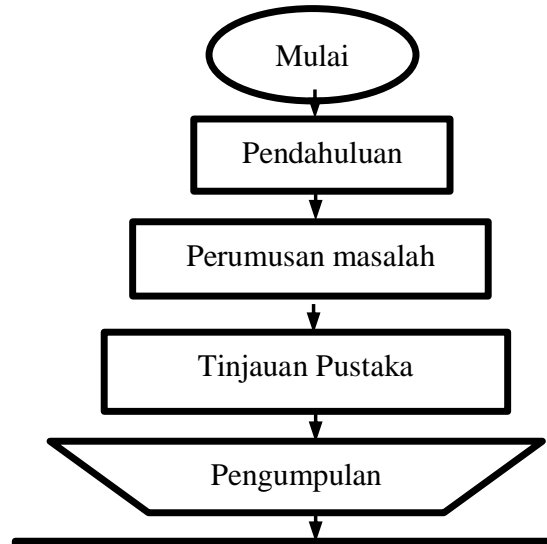

Analisis dan Pengolahan Data Metode SPSS

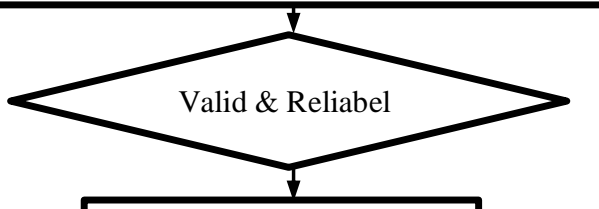

Perhitungan skala likert

$+$

Kesimpulan dan Saran

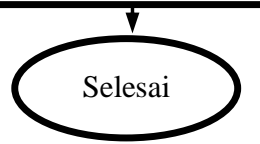

Sumber:Penulis, 2019

\section{Gambar 1. Diagram Alir Penelitian}

\subsection{Metode Analisis Deskriptif}

Metode yang digunakan dalam penelitian ini adalah metode deskriptif yang digunakan untuk mengetahui gambaran atau penyebaran sampel atau populasi, sehingga penelitian ini dimaksudkan untuk mengevaluasi penerapan SMK3 pada proyek bangunan pemerintah tidak sederhana di kota Ambon berdasarkan hasil penyebaran kuesioner dan wawancara.

\subsection{Teknik Pengolahan Data}

Analisa data yang dilakukan untuk menganalisa penerapan SMK3 pada proyek - proyek terkait di kota Ambon, dengan proses analisa sebagai berikut :

* Uji validitas dilakukan dengan menggunakan Pearson Corelation, pedoman suatu model dikatakan valid jika tingkat signifikansinya dibawah 0,05 , maka butir pernyataan tersebut dikatan valid. Penelitian ini, nilai $r$ tabel yang digunakan adalah 0,361 sesuai dengan nilai responden yang bernilai 30 orang.

* Uji reliabilitas ini menggunakan cornbach alpha dengan bantuan program statistic. Suatu variabel 


\section{JURNAL SIMETRIK VOL.9, NO.2, DESEMBER 2019}

dapat dikatakan reliabel apabila cornbach alpha > 0,6 ( Ghozali, $2005: 42$ )

* Data yang telah diberikan oleh responden dalam kuisioner yang telah disebar. Akan diolah dan digunakan untuk memberikan penjelasan.

* Sewaktu menanggapi pertanyaan dalam skala Likert, responden menentukan tingkat persetujuan mereka terhadap suatu pernyataan dengan memilih salah satu dari pilihan yang tersedia. Biasanya disediakan pilihan skala dengan format seperti ini:
1. STS : Sangat tidak setuju
2. TS : Tidak setuju
3. $\mathrm{S}$ : Setuju
4. SS : Sangat Setuju

Untuk perhitungan presentasenya, nilai rata- rata dari skor jawaban responden, maka digunakan rumus “Analisis Soal Tes” (Surakhmad,1994) sebagai berikut :

$\mathrm{K}=\frac{\mathrm{B}}{\mathrm{N}} \times 100 \%$

Dimana :

$\mathrm{K}$ : Skor Rata-Rata

B : Jumlah Skor yang Diperoleh masing- masing Variabel

$\mathrm{N}$ : Jumlah Skor Makssimal

\section{HASIL DAN PEMBAHASAN 4.1 Lokasi Penelitian}

Tabel 1. Proyek Penelitian

\begin{tabular}{|l|l|l|l|l|l|}
\hline No & PROYEK & $\begin{array}{l}\text { PELAKS } \\
\text { ANA }\end{array}$ & $\begin{array}{l}\text { DUR } \\
\text { ASI }\end{array}$ & $\begin{array}{l}\text { NILAI } \\
\text { KONT } \\
\text { RAK }\end{array}$ & KLASIFIKASI \\
\hline 1 & $\begin{array}{l}\text { Rumah dinas } \\
\text { Kawasan } \\
\text { Angkatan } \\
\text { Laut Tawiri }\end{array}$ & $\begin{array}{l}\text { PT Adhi } \\
\text { Daya } \\
\text { Evaniata } \\
\text { ma }\end{array}$ & $\begin{array}{l}210 \\
\text { Hari }\end{array}$ & $\begin{array}{l}\text { Rp } \\
7.836 .1 \\
83.00\end{array}$ & $\begin{array}{l}\text { Bangunan Rumah } \\
\text { Dinas Tipe B, D,E } \\
\text { yang lebih dari 2 } \\
\text { lantai }\end{array}$ \\
\hline 2 & $\begin{array}{l}\text { Pembanunan } \\
\text { Ruang Kantor } \\
\text { Kejaksaan } \\
\text { Tinggi }\end{array}$ & $\begin{array}{l}\text { CV } \\
\text { Venita } \\
\text { Sakti }\end{array}$ & $\begin{array}{l}\text { Hari } \\
\text { Maluku }\end{array}$ & $\begin{array}{l}\text { Rp } \\
1.627 .6 \\
46.000\end{array}$ & $\begin{array}{l}\text { Rehabiitasi } \\
\text { gedung kantor } \\
\text { lebih dari 500 } \mathrm{m}^{2} \\
\text { dan bertingkat } \\
\text { lebih dari 2 lantai }\end{array}$ \\
\hline 3 & $\begin{array}{l}\text { Pembangunan } \\
\text { Kantor PU } \\
\text { Prov Maluku }\end{array}$ & PT Cipta & $\begin{array}{l}120 \\
\text { Hutama }\end{array}$ & $\begin{array}{l}\text { Rp } \\
2.662 .8 \\
00.00\end{array}$ & $\begin{array}{l}\text { Rehabiitasi } \\
\text { gedung kantor } \\
\text { lebih dari 500 } \mathrm{m}^{2}\end{array}$ \\
\hline
\end{tabular}

Sumber: Hasil observasi, 2019

\subsection{Responden}

Jumlah responden dalam penelitian ini berjumlah 30 orang Berikut ini adalah deskipsi mengenai identitas responden penelitian mulai dari jenis kelamin, usia pendidikan terakhir. sebanyak 30 responden atau $100 \%$ berjenis kelamin laki - laki. Responden $19-25$ tahun berjumlah 3 orang dengan presentasi sebesar $10 \%$, usia responden $25-35$ tahun berjumlah 14 orang dengan presentasi sebesar $46.7 \%$, usia responden pada usia 35 - 50 tahun berjumlah 7 orang dengan presentasi sebesar $23.3 \%$ dan jumlah responden lebih dari 50 tahun berjumlah 6 orang dengan presentasi $20 \%$ responden yang memiliki tingkat pendidikan D3 berjumlah 7 orang dengan presentasi $23.3 \%$, responden yang memiliki tingkat pendidikan S1 berjumlah 20 orang dengan jumlah presentasi $66.7 \%$, sedangkan tingkat pendidikan S2 berjumlah 3 orang dengan presentasi $10 \%$.

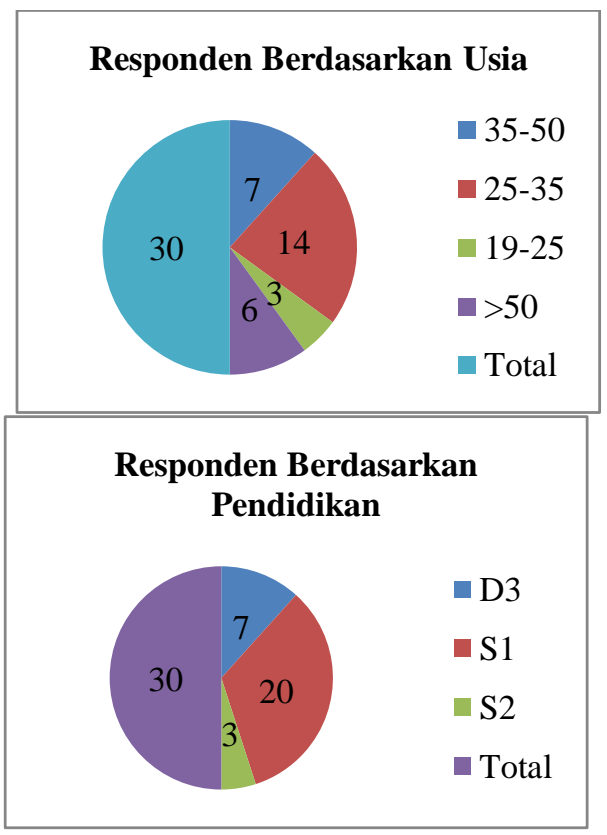

Sumber: Hasil observasi, 2019

\section{Gambar 2. Infografis Responden berdasarakan Usia dan pendidikan}

\subsection{Uji Validitas}

Uji validitas ini menggunakan metode Pearson Corelation, Pedoman suatu model dinyatakan valid jika tingkat signifikannya dibawah 0,05 maka butir pertanyaan tersebut dapat dikatakan valid. Tabel berikut menunjukan hasil uji validitas dari 5 faktor pentingyang digunakan dalam penelittian ini, yaitu faktor Peraturan/Standar Operasional, Faktor Individu Pekerja, Fakor Lingkungan Proyek, Faktor Manajemen, Faktor pelaksanaan Kesehatan dan Keselamatan kerja 


\section{JURNAL SIMETRIK VOL.9, NO.2, DESEMBER 2019}

Tabel 2. Hasil uji validitas

\begin{tabular}{|c|c|c|c|}
\hline o & Faktor & $\mathrm{V}$ & Pearson Corelation \\
\hline \multirow[t]{4}{*}{1} & \multirow{4}{*}{$\begin{array}{l}\text { Peraturan dan } \\
\text { standart } \\
\text { Keselmatan } \\
\text { kerja }\end{array}$} & Q1 & $0.892>0.361$ \\
\hline & & Q2 & $0.925>0.361$ \\
\hline & & Q3 & $0.897>0.361$ \\
\hline & & Q4 & $0.673>0.361$ \\
\hline \multirow[t]{5}{*}{2} & \multirow[t]{5}{*}{ Individu } & Q1 & $0.586>0.361$ \\
\hline & & Q2 & $0.715>0.361$ \\
\hline & & Q3 & $0.833>0.361$ \\
\hline & & $\mathrm{Q} 4$ & $0.874>0.361$ \\
\hline & & Q5 & $0.515>0.361$ \\
\hline \multirow[t]{4}{*}{3} & \multirow{4}{*}{$\begin{array}{l}\text { Lingkungan } \\
\text { Proyek }\end{array}$} & Q1 & $0.426>0.361$ \\
\hline & & $\mathrm{Q} 2$ & $0.607>0.361$ \\
\hline & & Q3 & $0.604>0.361$ \\
\hline & & Q4 & $0.583>0.361$ \\
\hline \multirow[t]{4}{*}{4} & \multirow{4}{*}{$\begin{array}{l}\text { Faktor } \\
\text { Manajemen } \\
\text { K3 }\end{array}$} & Q1 & $0.426>0.361$ \\
\hline & & $\mathrm{Q} 2$ & $0.897>0.361$ \\
\hline & & Q3 & $0.604>0.361$ \\
\hline & & Q4 & $0.583>0.361$ \\
\hline \multirow[t]{5}{*}{5} & \multirow{5}{*}{$\begin{array}{l}\text { Faktor } \\
\text { Kesehatan } \\
\text { Kerja }\end{array}$} & Q1 & $0.734>0.361$ \\
\hline & & Q2 & $0.532>0.361$ \\
\hline & & Q3 & $0.980>0.361$ \\
\hline & & Q4 & $0.957>0.361$ \\
\hline & & Q5 & $0.584>0.361$ \\
\hline
\end{tabular}

Sumber: Hasil analisis, 2019

\subsection{Uji Reliabilitas}

Tabel 3. Hasil uji reliabilitas

\begin{tabular}{|c|l|c|}
\hline No & Faktor & $\begin{array}{c}\text { Cornbach } \\
\text { Alpha }\end{array}$ \\
\hline 1 & Standar Operasional & 0.822 \\
\hline 2 & Individu Pekerja & 0.822 \\
\hline 3 & Lingkungan & 0.693 \\
\hline 4 & Manajemen Proyek & 0.963 \\
\hline 5 & Kesehatan Kerja & 0.693 \\
\hline
\end{tabular}

Sumber: Hasil analisis, 2019

Dari hasil uji reliabilitas menggunakan metode cronbach alpa dengan bantuan program statistic, didapatkan nilai alpha untuk setiap variabel dalam faktor individu pekerja nilai Alpha Cronbach $(\alpha)$ diatas 0,6. Hal ini menunjukan variabel - variabel tersebut dapat dikatakan reliabel.

\subsection{Hasil Perhitungan skala likert}

Dibawah ini akan diuaraikan hasil uji menggunakan perhitungan bobot skala likert yang ditinjau berdasarkan masing - masing aspek dari penerapan sistem manajemen kesehatan dan keselamatan kerja (SMK3) dan faktor - faktor yang sangat kurang dalam pelaksanaan SMK3 pada proyek bangunan pemerintah tidak sederhana di Kota Ambon.

Tabel 4. Hasil perhitungan skala likert

\begin{tabular}{|l|l|l|l|l|l|l|}
\hline indikator & SS & S & TS & STS & TOTAL & $\%$ \\
\hline Q1 & 7 & 16 & 7 & 0 & 90 & 75.5 \\
\hline Q2 & 6 & 7 & 12 & 5 & 74 & 61.67 \\
\hline Q3 & 11 & 9 & 8 & 2 & 89 & 74.17 \\
\hline Q4 & 5 & 7 & 9 & 9 & 68 & 56.67 \\
\hline Q5 & 18 & 12 & 0 & 0 & 108 & 90.00 \\
\hline Q6 & 12 & 13 & 1 & 4 & 93 & 77.50 \\
\hline Q7 & 8 & 6 & 15 & 0 & 80 & 66.67 \\
\hline Q8 & 10 & 0 & 11 & 9 & 71 & 59.17 \\
\hline Q9 & 6 & 0 & 19 & 5 & 67 & 55.83 \\
\hline Q10 & 14 & 9 & 7 & 0 & 97 & 80.83 \\
\hline Q11 & 19 & 5 & 6 & 0 & 103 & 85.83 \\
\hline Q12 & 22 & 8 & 0 & 0 & 112 & 93.33 \\
\hline Q13 & 7 & 3 & 1 & 20 & 58 & 48.33 \\
\hline Q14 & 12 & 0 & 8 & 10 & 74 & 61.67 \\
\hline Q15 & 3 & 6 & 16 & 5 & 67 & 55.83 \\
\hline Q16 & 5 & 9 & 13 & 3 & 76 & 63.33 \\
\hline Q17 & 9 & 4 & 6 & 11 & 71 & 59.17 \\
\hline Q18 & 0 & 0 & 8 & 22 & 38 & 31.67 \\
\hline Q19 & 0 & 0 & 3 & 27 & 33 & 27.50 \\
\hline Q20 & 8 & 3 & 12 & 7 & 72 & 60 \\
\hline Q21 & 7 & 6 & 15 & 2 & 78 & 65 \\
\hline Q22 & 8 & 3 & 19 & 0 & 79 & 65.83 \\
\hline
\end{tabular}

Sumber: Hasil analisis, 2019

Berdasarkan hasil analisa terhadap penilaian penerapan sistem manajemen keselamatan dan kesehatan kerja ( SMK3) pada proyek bangunan pemerintah sederhana di kota Ambon, terhadap kuesioner yang dibagikan kepada responden terdapat beberapa indikator yang menjadi faktor terendah yang menjadi penghambat dalam penerapan sistem manajemen keselamatan dan kesehatan kerja (SMK3) pada proyek bangunan pemerintah sederhana di kota Ambon.

Tabel 5. Indikator Terendah Penerapan SMK3

\begin{tabular}{|l|l|l|l|l|}
\hline No & faktor & Pernyataan & $\%$ & Ket \\
\hline 1 & $\begin{array}{l}\text { Peraturan dan } \\
\text { Operasional }\end{array}$ & $\begin{array}{l}\text { Sanksi dari perusaahan } \\
\text { jika melanggar }\end{array}$ & 56.67 & Kurang \\
\hline 2 & $\begin{array}{l}\text { Individu } \\
\text { Pekerja }\end{array}$ & $\begin{array}{l}\text { Menolak pekerjaan } \\
\text { yang membahayakan }\end{array}$ & 49.17 & kurang \\
\hline 3 & $\begin{array}{l}\text { Lingkungan } \\
\text { proyek }\end{array}$ & $\begin{array}{l}\text { Menyediakan pintu } \\
\text { darurat }\end{array}$ & 48.33 & kurang \\
\hline 4 & $\begin{array}{l}\text { Factor } \\
\text { manajemen }\end{array}$ & $\begin{array}{l}\text { Mendapatkan } \\
\text { sosialisasi tentang K3 }\end{array}$ & 55.83 & Kurang \\
\hline 5 & $\begin{array}{l}\text { Factor } \\
\text { Pelaksanaan K3 }\end{array}$ & $\begin{array}{l}\text { Melakukan } \\
\text { pemeriksaan sebelum } \\
\text { mulai kerja }\end{array}$ & 31.67 & Kurang \\
\hline
\end{tabular}

Sumber: Hasil analisis, 2019

\subsection{Pencegahan Yang Dapat Dilakukan Untuk Mengatasi Keterbatasan SMK3}

Solusi yang dapat dilakukan untuk mengatasi penerapan yang paling kurang adalah : 


\section{JURNAL SIMETRIK VOL.9, NO.2, DESEMBER 2019}

1. Instansi pemerintah terkait dapat meneur dan mempertegas aturan tentang penerapan Keselamatan dan Kesehatan kerja agar perusahaan dapat lebih tegas mengeluarkan peraturan pada proyek yang berlangsung

2. Perusahaan seharusnya memperkerjakan pekerja sesuai dengan kemampuan dan keahlian masingmasing individu

3. Perusahaan yang menjalankan proyek harus lebih sering melakukan sosialisasi bagi para pekerja mengenai pentingnya keselamatan dan kesehatan kerja di lapangan saat bekerja

\section{PENUTUP}

\subsection{Kesimpulan}

Presentasi penerapan keselamatan dan kesehatan kerja yang paling kurang adalah

1. Sanksi dari perusahaan jika melangar $(56.67 \%)$ solusi yang dapat dilakukan adalah pemerintah atau instansi terkait lebih memperhatiakan proyekproyek yang sedang berlangsung.

2. Pekerja dapat menolak pekerjaan yang membahayakan $(49.17 \%)$ solusi yang dapat dilakukan adalah dengan memperkerjakan pekerja sesuai dengan keahlian masing- masing.

3. Perusahaan Menyediakan pemadam kebakaran dan pintu darurat $(48.33 \%)$ solusi yang dapat dilakukan adalah perusahan lebih memperhatikan jalur aman.

4. Pekerja mendapatkan sosialisasi tentang K3 $(55.83 \%)$ solusi yang dapat dilakuakn adalah perusahaan lebih mendorong petugas K3 untuk menjalankan fungsi agar pekerja juga mampu mengetahui peran penting SMK3.

5. Pemeriksaan Kesehatan berkala (27.50\%) solusi yang dapat dilakukan adalah menyediakan tenaga medis khusus bagi pekerja di tempat kerja.

\subsection{Saran}

Agar Penelitian ini lebih akurat di masa mendatang hendaknya peneliti selanjutnnya dapat menambah variasi dan faktor penerapan system manajemen keselamatan dan kesehatan kerja, menambah responden, serta tempat penelitian.

\section{DAFTAR PUSTAKA}

Hendra T., 2015, Tinjauan Penerapan Sistem Manajemen Keselamatan dan Kesehatan Kerja Kota Pekan Baru, Jom FTEKNIK Volume 3 No. 2, Pekanbaru

Pangkey., F, 2012, Penerapan Sistem Manajemen Keselamatan Dan Kesehatan Kerja (SMK3) Pada Proyek Konstruksi di Indonesia, Jurnal Ilmiah Media Enginering volume 2 nomor 2, Manado

Peraturan Mentri Tenaga Kerja Republik Indonesia, 1980. No 1 Tahun 1980 tentang K3 Pada Konstruksi Bangunan
Peraturan Menteri PU dan Tenaga Kerja Republik Indonesia, 1986, No 174 tahun 1986 tentang K3 pada Tempat Kegiatan Konstruksi

Peraturan Menteri Tenaga Kerja, 1996, Nomor : Per. 05/Men/1996 Tentang Sistem Manajemen Keselamatan Dan Kesehatan Kerja

Peraturan Menteri Pekerjaan Umum Republik Indonesia, 2007, No 45 tentang Bangunan Pemerintah Tidak Sederhana

Peraturan Menteri Republik Indonesia, 2008, PU No 9 Tahun 2008 tentang Manajemen Keselamatan Dan Kesehatan Kerja

Peraturan Pemerintah Republik Indonesia, 2012, tentang Sistem Manajemen Keselamatan Dan Kesehatan Kerja

Sembiring, S., 2008, Penerapan Sistem Manajemen Keselamatan Dan Kesehatan Kerja, Jurnal Evaluasi Penerapan Sistem Manajemen Pada Proyek Pembangunan Gedung, Medan

Surakhmad, W., 1994, Pengantar Penelitian Ilmiah dasar Metode Teknik, Tarsito, Bandung

Undang - Undang Republik Indonesia, 1970, No. 1 Tahun 1970 tentang Keselamatan Kerja

Undang - Undang Republik Indonesia, 1999, No 18 Tahun 1999 Tentang Jasa Konstruksi

Undang - Undang Republik Indonesia, 2000, No 50 tahun 2000 tentang Sistem Manajemen Keselamatan dan kesehatan Kerja

Undang - Undang Republik Indonesia, 2003, No 13 tentang Ketenagakerjaan 